\title{
Pre University Students Proficiency in Symbols, Graphs and Problem-Solving and Their Economic Achievement
}

\author{
Arsaythamby Veloo $^{1} \&$ Ruzlan Md-Ali ${ }^{2}$ \\ ${ }^{1}$ School of Education and Modern Languages, Universiti Utara Malaysia, Malaysia (UUM) 06010 Sintok, \\ Kedah, Malaysia \\ ${ }^{2}$ Institute for Advanced Research in Education (IARE), UUM College of Arts and Sciences, Universiti Utara \\ Malaysia, Malaysia (UUM) 06010 Sintok, Kedah, Malaysia \\ Correspondence: Arsaythamby Veloo, School of Education and Modern Languages, Universiti Utara Malaysia, \\ Sintok, Kedah, Malaysia. E-mail: arsay@uum.edu.my
}

Received: March 23, 2015 Accepted: June 29, $2015 \quad$ Online Published: July 30, 2015

doi:10.5539/res.v7n11p263 URL: http://dx.doi.org/10.5539/res.v7n11p263

\begin{abstract}
The purpose of this study is to identify the level of difficulty of symbols, graphs and problem-solving items in Economic achievement among pre university students. The sample comprised of 110 students from national daily secondary schools in the state of Kedah, Malaysia. The achievement test comprised of 18 items with six symbol items, six graph items and six economic problem-solving items. The findings show that item difficulty indices for symbol items, graph items, and economic problem-solving items are $0.65,0.45$, and 0.49 respectively, which indicate that students in the study can understand items presented using symbols better than the graphs or economic problem-solving items. The students faced greater difficulty with graph items compared to economic problem-solving items. For symbol items, students faced difficulty in answering Item 2 (Saving Function-0.20) and Item 4 (Market Balance-0.28). For the graph items, the students had difficulty in answering Item 4 (Demand-0.25) and Item 2 [Two sectors $\mathrm{C}+\mathrm{I}-0.29$ ). For the Economics problem-solving items, students found it difficult to answer Item 5 (Tax-0.21). The findings in the study imply that a combination of symbol, graph and economic problem-solving items should be taken into account when constructing items for Pre University Economics tests.
\end{abstract}

Keywords: difficulty index, symbol, graph, problem-solving, economic achievement

\section{Introduction}

One of the subjects taken by pre university students in Malaysia is Economics, which is an elective subject, and its syllabus comprised of economic theories, economic systems, economic problems and solutions, and factors affecting economic activities. Pre university students sit for a public examination after a duration of three semesters of study. This examination is known as Malaysian Higher School Certificate (STPM) which is managed by the Malaysian Examination Council. The Economics examination paper comprised of economic concepts (47\%), symbol problem-solving (37\%), and graphs (16\%) (Malaysia Examination Council, 2011).

In Economics texts, the explanations are usually supported by data and graphs, which explain relationships between variables, for example the demand curve, supply curve, cost curve, production curve, saving and expenditure. Data and graphs are also used to explain the direction of flow of economic activities and the contribution of each economic sector. The Economics texts also include various terminologies which are unfamiliar to students, especially to those who are new to the Economics subject, for example the terms 'flexible demand', 'supplementary item', and 'free of charge item'.

Reading and understanding Economics texts is difficult (Parkin, 2005). Johnston and James (2000) in their study reported that students who took the Economics subject need to think abstractly and apply economic theories in everyday lives. The students also need to explain complex ideas logically and smoothly based on their understanding. According to Mayer (1985), among the reasons why the Economics subject is difficult to understand is readers do not have sufficient experiences in reading texts. Dymock (2005) suggested that readers face difficulty in reading Economics texts because they are not able to identify the basic structure of the text. This situation had caused the readers to lose focus and failed to look at the overall picture of the text. According 
to Cubukcu (2007), the acquisition of any subject is influenced by the knowledge about reading strategies and the practices in applying the particular strategy. In a study carried out by Johnston, James, Lye and McDonald (2000), it was found that to learn economics successfully, one must be capable of abstract thinking and also capable to apply this thinking when solving practical problems.

Mathematics and Statistics are the integral part of the Economics discipline and the importance of quantitative skills in Economics is recognized (Dawson, 2014). In a research carried out by Cadenas (1999), it was found that majority of the students perceived Economics subject as difficult. Johnson and James (2000) found that Economics subject was difficult for secondary students in Melbourne, Australia. In another study, Schuhmann et al. (2005) reported that students who were less able in quantitative skills will also face Economics achievement problems.

The Economics achievement of students who took Economics subject in school was low and with not very encouraging result (Malaysia Examination Board, 2011). The pre university Economics examination results indicated a decline in 2010 and 2011. The percentage of students obtaining a full pass in Economic examination in 2010 was $57.55 \%$, and the percentage decreased to $53.92 \%$ for the year 2011 .

Students show less interest in Economics subject if their performance in the subject is low. Khoo and Zakaria (2005) found that $75 \%$ of the students in their study faced difficulty to understand Economics concepts. Meanwhile, 58\% of the Economics students found it difficult to solve assignments which involve problem-solving that have mathematics elements. Additionally, in the same study, $69 \%$ of the students were facing difficulties in interpreting graphs to relate concepts and the relevant Economic theories. In a study by Khoo (2008), it was found that pre university Economics students frequently faced difficulties in understanding the concepts, data analysis and describing graphs.

\subsection{Economics Achievement Based on Symbol}

The Economic concepts are generally taught using the quantitative approach, which include the use of symbols and numbers. Students have great difficulties in using and interpreting symbols in Mathematics (Kinzel, 2001; Luo, 2004). In a study by Çelik and Güneş (2013), it was found that the majority of students had difficulty in using and interpreting literal symbols as generalized numbers. According to Greeno (1983), this difficulty in problem-solving using symbol knowledge can be interpreted as students had actually memorized what needs to be learned. Skemp (1982), on the other hand, interpreted this difficulty as procedural learning or understanding whereby strategy, procedures and component of the knowledge learned have limited adaptation in new situations or when encountering new problems. Hence, less meaningful learning had actually occurred.

\subsection{Economics Achievement Based on Graph}

Economics subject uses Statistics and Mathematics to analyze real-life problems (Dawson, 2014; Hansen, 2001; Cohn, Cohn, Hult, Balch \& Bradley, 1998). Students are usually not attracted to courses that use Mathematics and Statistics, and this dislike may account for the poor evaluation of Economics subjects (Ongeri, 2009). The Economics concepts are also taught using quantitative approaches, including the use of graphs. Students who are weak in quantitative understanding performed less than satisfactory in the Economics subject (Schuhmann, McGoldrick \& Burrus, 2005). Students possessing skills in Mathematics and Science have an advantage when learning the Economics subject (Caviglia-Harris, 2003). Experts in the Economics subject suggest that students ought to learn Mathematics before the subject (Schuhmann et al., 2005).

The ability to decode and encode when interpreting information is another skill needed in learning the Economics subject. Decoding involves the interpretation of graphs into mathematical statements whereas encoding involves interpretation of mathematical statements into graphs (Baker, Corbett, \& Koedinger, 2001; Diezmann, 2004). Lowrie and Diezman (2005) conjecture that students need to become code-breakers to acquire mathematical knowledge from graphs before they are able to solve Economics problems. Thus, the learning of Economics at the pre-university level has a relation to students' mathematics proficiency because most Economics concepts, theories, graphs and problem-solving are related to Mathematics. For example, the Economics paper in the STPM has items related to Economics concepts (47\%), symbols, problem-solving (37\%), and graphs (16\%) (Malaysia Examination Council, 2011), which indicates the importance of being mathematically competent in order to be competent in the Economics subject. Hence, it can be seen that the usage of Mathematics is necessary in ensuring the efficiency of the Economics curriculum implementation in schools.

It has been widely agreed that graphs are important in education, the learning process and mathematical understanding (Cucuo \& Curcio, 2001). Even though our society uses a lot of graphical information for 
administration, communication and information analysis (Harris, 1996), researchers have placed less attention on the interrelationship between numbers and graphs (Pugalee, 1999). This relationship involves the ability of an individual to decode mathematical information from graphs and codes mathematical information into graphs (Diezmann, 2004).

Research on the use of images are limited (Postigi \& Pozo, 2004), despite the increasing importance of this skill (Lowrie, 2005). Postigo and Poza (2004) conjecture that research being implemented within the area of Mathematics are very wide because graphs, figures and numerical graphs have specific syntaxes and conventions. Lowrie and Diezmann (2005) point out that students need to become code breakers to obtain mathematical information from graphs which are used in the tasks, texts, tests, software and everyday situations.

In mathematics, a graph is expressed based on the characteristics of the graph (curve \& linear graphs) of a function, e.g., $x$-intercept, (root), y-intercept, maximum point, minimum point, point of inflection, shape of the graph and sketching graphs. The graphs used in the Economics subject are similar to the graphs used in Mathematics. Economics teachers have used various creative teaching methods to encourage continuous understanding of the subject among their students. Basic Economics concepts are usually taught using quantitative methods, including the use of graphs and numeric examples as well as their applications (Cadenas, 1999).

\subsection{Economics Achievement Based on Problem-Solving}

Problem-solving methods have long been used in the teaching and learning of Science and Mathematics but have not been extensively used in the teaching and learning of Macroeconomics despite the fact that problem-solving methods are very much needed for meaningful learning. Additionally, research carried out in Australia and New Zealand by Johnston and James (2000) found that problem-solving methods are very relevant to be used as a benchmark especially for the Economics subject.

Khoo (2008) found that problem-solving methods can serve as useful guidelines for teachers in planning their teaching and learning strategies which are relevant to train critical thinking among students. Subsequently, Economics teachers have the opportunities to expose their students to active learning methods, to implement critical thinking in classrooms and to guide their students towards an in-depth understanding of Microeconomics. Moreover, the methods can also assist students to increase their performance, interest and readiness in learning Economics. Khoo also found that problem-solving methods can contribute to the efforts made by policy makers in enhancing the quality of services provided by educational institutions. These efforts are important in providing satisfaction to the customers through good and quality services. Continuous research and development in the problem-solving methods can provide findings which could contribute towards the move to make Malaysia a centre of excellence in education within this region and ultimately place the field of education in Malaysia to be comparable to world standards.

\section{Research Objectives}

The objectives of this study are:

1) To identify the level of Economics achievement based on symbols, graphs and problem-solving among pre university students.

2) To identify the items difficulty level based on symbols, graphs and problem-solving towards Economics achievement among pre university students.

\section{Methodology}

In this descriptive quantitative study, simple random sampling was used to select 110 pre university students from daily national secondary schools in the state of Kedah that offered the Economics subject. The Economics test comprised of 18 items with six items for symbols, graphs and economic problem-solving respectively. The total marks for the Economics test was 50, in which the marks for symbols was 14, for graphs was 16, and for problem-solving was 20. To ensure content validity, all selected items (symbols, graphs, \& economic problem-solving) were aligned with the Economics syllabus before submitting them to a panel of evaluators which comprised of three Economics subject specialist teachers. The researchers had requested the help of the Economics teachers, who were briefed on the purpose of the study and procedures for administering the study's test, to administer the test to their selected students and to collect the answer scripts. The teachers were given a time frame of one week to administer the test within their respective schools.

The researchers had determined the difficulty index (p) of the test, which was defined as the percentage or rate of number of students who had given correct responses compared to the overall number of people who answered 
the items. Theoretically, difficulty index has a value from zero until one. Items that have a difficulty index below 0.30 are classified as having a high level of difficulty and those above 0.70 are considered to be low level. Items that have a difficulty index between 0.30 and 0.70 are considered to have a moderate level of difficulty (Kaplan \& Saccuzzo, 2001).

The formula below measures the difficulty index of the items:

$\Sigma \mathrm{fX}=$ the sum of the frequency multiplied by the score

$$
\text { Difficulty Index }(\mathrm{p})=\frac{\Sigma f X-n(X \text { minimum })}{n(X \text { Max }-X \text { Min })}
$$

$\mathrm{n}=$ total number of students

$\mathrm{X} \max =$ maximum score

$\mathrm{X} \min =$ minimum score

\section{Findings}

\subsection{The Level of Economic Symbol Achievement}

Table 1 indicates the distribution of scores for symbol achievement in the Economics test which ranges between 0-13 marks. For symbol achievement, the score with the most number of students is 10 marks and the total number of students obtaining this mark is 29 . The mean score for symbol achievement is 8.39 and the mode is 10 . The number of students obtaining marks below the mean score is $49(45 \%)$. Meanwhile 61 students $(55 \%)$ had obtained marks above the mean score.

Table 1. Distribution of students' scores in Economics symbol achievement

\begin{tabular}{ccc}
\hline Score $(\mathrm{x})$ & Frequency $(\mathrm{f})$ & $\mathrm{fx}$ \\
\hline 0 & 1 & 0 \\
3 & 1 & 3.0 \\
4 & 7 & 28.0 \\
5 & 12 & 60.0 \\
6 & 3 & 18.0 \\
7 & 14 & 98.0 \\
8 & 11 & 88.0 \\
9 & 13 & 117.0 \\
10 & 29 & 290.0 \\
11 & 8 & 88.0 \\
12 & 10 & 120.0 \\
13 & 1 & 13.0 \\
\hline Total & 110 & 923.0 \\
\hline
\end{tabular}

\subsection{The Economics Symbol Items Difficulty Level}

Overall, the difficulty index for symbol achievement is 0.65 (Table 2). This shows that $65 \%$ of the students had correctly answered the symbol item compared to $35 \%$ who had failed to correct them. Hence, the symbol items were seemingly easy for the students.

Table 2. Difficulty indices for Economics symbol achievement

\begin{tabular}{cccc}
\hline $\mathrm{n}(\min )$ & $\sum f x-n($ min $)$ & $n($ max - min $)$ & $p$ \\
& & $=\frac{\sum f x-n(\min )}{n(\max -\min )}$ \\
\hline 0 & 923.0 & 1430 & 0.65 \\
\hline
\end{tabular}


The symbol test comprised of six items which were constructed based on the pre university Economics syllabus. When ranked from the most difficult to the most easy, the item difficulty levels for symbol (S) items were as follows: item S2 (0.20), S4 (0.28), S3 (0.56), S6 (0.62), S1 (0.85) and S5 (0.92). Item S1 (Market Equilibrium) was easy since $85 \%$ of the students were able to answer this item and its difficulty index is 0.85 (Table 2). For item S2 (Deposit Function), only 20\% of the students had answered the item correctly whereas $80 \%$ were not able to answer the item correctly. Hence, this situation indicates that item S2 is a very difficult item for the students. 56\% of the students had correctly answered item S3 (Demand Function), which was of average difficulty since the difficulty index was 0.56 . Item S4 (Market Equilibrium) was another difficult item whereby $72 \%$ of the students failed to answer it. This item had a high difficulty level with the difficulty index being 0.28 . For item S4, only $28 \%$ of the students could correctly answer the item and $72 \%$ were not able to answer the item correctly (Figure 1).

Item S5 (National Income Equilibrium) was the easiest since its difficulty index was 0.92 and $92 \%$ of the students were able to correctly respond to the item. The difficulty level of item S6 (National Income Equilibrium) was average and its difficulty index was 0.62 . $62 \%$ of the students were able to answer the item correctly and $38 \%$ had failed to obtain any score for the item.

From all the six symbol items, item S2 and item S4 were the most difficult items and items S1 and S5 were the easiest. For symbol achievement, the high number of students obtaining scores above the mean score indicates that the symbol items were easy for them. The item difficulty indices were also generally high, which is 0.65 (Figure 1). Hence, this indicates that the symbol items in the Economics subject are moderately easy for the students.

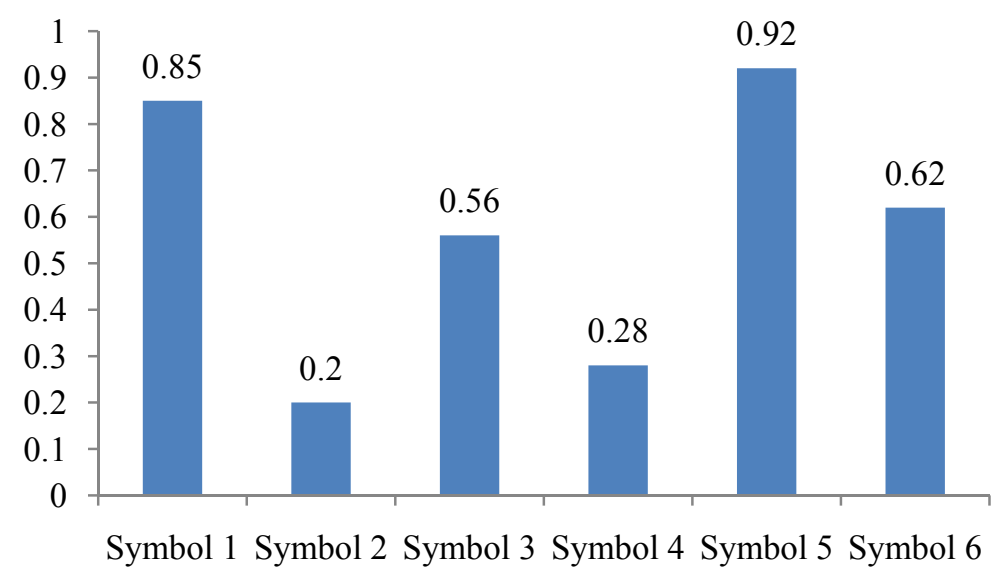

Figure 1. The difficulty indices according to Economics symbol items

\subsection{The Level of Economics Graph Achievement}

Table 3 indicates the distribution of graph achievement scores in the Economics subject, which ranges from 0-16 marks. 16 students had obtained 12 marks, which was the marks with the most number of students achieving it. Ten students had not obtained any marks and this situation indicates that these students had failed to answer the graph items. The maximum score was 16 but only two students had obtained this score. The finding of this study shows that the average score of graph achievement is 7.25 and the mode is 12 . The number of students obtaining the marks below the mean score is $53(48.50 \%)$. Meanwhile 57 students $(51.50 \%)$ had obtained marks above the mean score. 
Table 3. Distribution of students Economics graph achievement scores

\begin{tabular}{ccc}
\hline Marks(x) & Frequency $(\mathrm{f})$ & $\mathrm{fx}$ \\
\hline 0 & 10 & 0 \\
1 & 6 & 6.0 \\
2 & 10 & 20.0 \\
3 & 2 & 6.0 \\
4 & 9 & 36.0 \\
5 & 5 & 25.0 \\
6 & 5 & 30.0 \\
7 & 6 & 42.0 \\
8 & 8 & 64.0 \\
9 & 4 & 36.0 \\
10 & 13 & 130.0 \\
11 & 3 & 33.0 \\
12 & 16 & 192.0 \\
13 & 9 & 117.0 \\
14 & 1 & 14.0 \\
15 & 1 & 15.0 \\
16 & 2 & 32.0 \\
\hline Total & 110 & 792.0 \\
\hline
\end{tabular}

\subsection{The Economics Graph Item Difficulty Level}

Overall, the graph achievement had a difficulty index of 0.45 , which revealed that only $45 \%$ of the students had successfully answered the graph items compared to $65 \%$ students who were not able to correctly answer them. Students viewed that in the Economics subject, the graph items were very difficult to understand (Table 4).

Table 4. Difficulty index for Economics graph achievement

\begin{tabular}{cccc}
\hline $\mathrm{n}(\mathrm{min})$ & $\sum f x-n($ min $)$ & $n($ max - min $)$ & $p=\frac{\sum f x-n(\min )}{\mathrm{n}(\max -\min )}$ \\
\hline 0 & 798 & 1760 & 0.45 \\
\hline
\end{tabular}

The graph test comprised of six objective items. The graph (G) items difficulty, when ranked from the most difficult to the easiest, is as follows: item G4 (0.25), G2 (0.29), G1 (0.31) (Market Equilibrium), G5 (0.40) (National Income), G3 (0.43) (Supply Concept) and G6 (0.51) (Table 3). from all the six items, item G4 (C + I Two Sectors Function) was the most difficult item for only $25 \%$ of the students had answered the item correctly compared to $75 \%$ who were not able to answer the item (Figure 3). Item G2 (Demand Concept) was the second difficult item in which only $29 \%$ of the students had successfully answered the item compared to another $71 \%$ who failed to correctly answer the item. The easiest item for the students was item G6 (Investment) (Figure 2). 


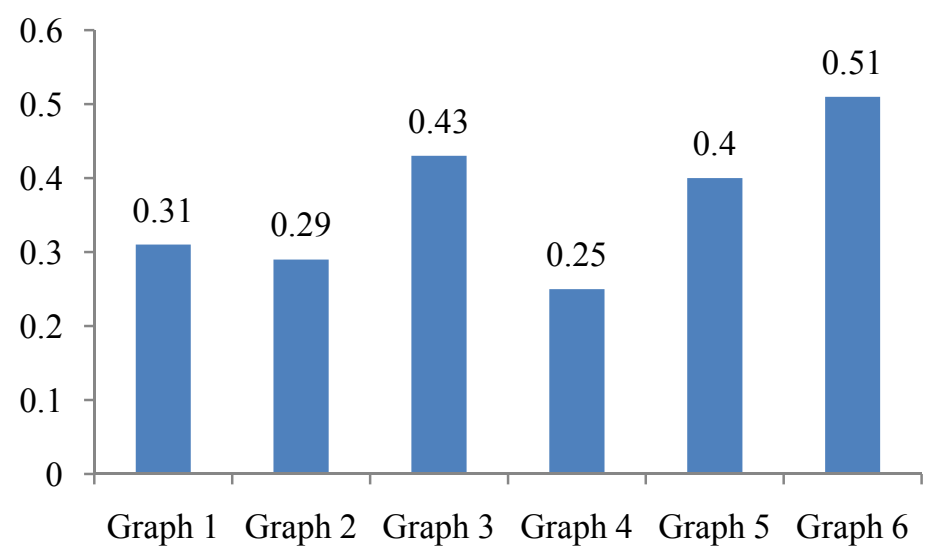

Figure 2. Difficulty indices according to graph achievement items

\subsection{The Level of Economics Problem-Solving Achievement}

The scores for problem-solving achievement in the Economics subject were distributed between the minimum score 0 and the maximum score 16 . The number of students who obtained four marks is 21 . There were eight students who did not obtain any marks for Economics problem-solving (Table 5).

Table 5. Distribution of students' scores in Economics problem-solving achievement

\begin{tabular}{ccc}
\hline Score $(\mathrm{x})$ & Frequency (f) & fx \\
\hline 0 & 8 & 0 \\
1 & 1 & 1.0 \\
3 & 1 & 3.0 \\
4 & 21 & 84.0 \\
5 & 3 & 15.0 \\
6 & 10 & 60.0 \\
7 & 10 & 70.0 \\
8 & 11 & 88.0 \\
9 & 6 & 54.0 \\
10 & 8 & 80.0 \\
11 & 6 & 66.0 \\
12 & 9 & 108.0 \\
13 & 9 & 117.0 \\
14 & 2 & 28.0 \\
16 & 5 & 80.0 \\
\hline Total & 110 & 854.0 \\
\hline
\end{tabular}

\subsection{The Economics Problem-Solving Difficulty Level}

Overall, problem-solving achievement had a difficulty index of 0.49 , which indicated that only $49 \%$ of the students had correctly answered the problem-solving items compared to $51 \%$ of the students who were not able to correctly answer them. Students viewed the problem-solving items in the Economics subject as moderately difficult to understand (Table 6). 
Table 6. Difficulty indices for Economics problem solving

\begin{tabular}{cccc}
\hline $\mathrm{n}(\min )$ & $\sum \mathrm{fx}-\mathrm{n}(\min )$ & $\mathrm{n}(\max -\min )$ & $p=\frac{\sum f x-n(\min )}{n(\max -\min )}$ \\
\hline 0 & 854.0 & 1760 & 0.49
\end{tabular}

For the economics problem-solving items, only $5 \%$ of the students had managed to answer item PS4 (Nation Income) correctly. On the other hand, for item 5 (Taxes), only $21 \%$ of the students had correctly answered the item (Figure 3). There were six items in the Economics test that catered for problem-solving (PS). The item difficulty levels for PS items, from easy to difficult, were as follows: item PS4 (0.05), PS5 (0.21), PS1 (0.38), PS3 (0.43), PS6 (0.44) and PS2 (0.82). Item PS2 (Market Equilibrium) was the easiest item, whereby $82 \%$ of students had correctly answered it and $18 \%$ of students had failed to answer it correctly. On the other hand, only $5 \%$ of students were able to answer item PS4 and 95\% of the students were not able to answer this item correctly. For item PS5 (Taxes), only $21 \%$ of the students had answered the item correctly compared to $79 \%$ who were not able to answer the item. Hence, after item PS4, item PS5 was a difficult item. Item PS1 (Supply Elasticity), with a difficulty index of 0.38 , was the third difficult item for students. Items PS3 (Market Equilibrium) and PS6 (Consumer Function) had average difficulty since the difficulty index indices were 0.43 and 0.44 respectively (Figure 3 ).

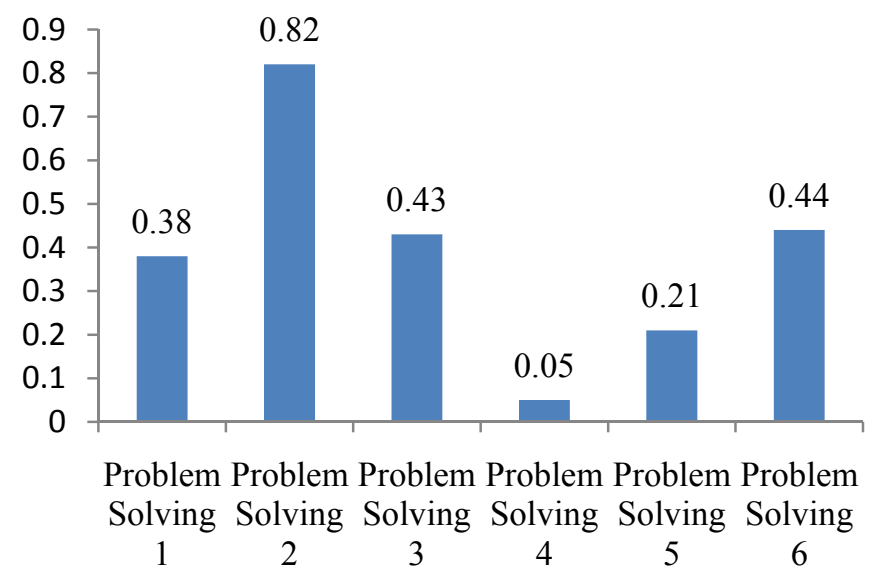

Figure 3. Difficulty index according to Economics problem-solving items

\section{Discussion}

\subsection{Difficulty of Symbol, Graph and Problem-Solving in Economic Achievement}

The difficulty indices for symbols, graphs and problem-solving are $0.65,0.45$, and 0.49 respectively indicate that symbols are the easiest and graphs are the most difficult for the students in this study. For Economics symbol, the percentage of students obtaining marks below the mean score is $45 \%$ and $55 \%$ had obtained marks above the mean score, which indicates that the Economics symbol was easy for the students. The finding contradicted the findings of Çelik and Güneş, (2013), Kinzel (2001), and Luo (2004) studies which were found that the majority of students in their study had difficulty in using and interpreting literal symbols as generalized number.

This study found that $65 \%$ of the students were not able to correctly answer the graph items, which show that graph items were very difficult for them to answer. This difficulty could be due to students' lacking in proficiency in quantitative understanding as suggested by Ongeri (2009) and Schuhmann, McGoldrick and Burrus (2005). The findings in this study support the findings of Khoo (2008) who had reported that Economics students faced difficulty in graphs explanation. The findings in this study further support Caviglia-Harris (2003) conjecture that students possessing skills in Mathematics have an advantage when learning the Economics subject because graphs is a part of Mathematics and the Economics subjects. It can be reasonably concluded that proficiency in graphs has a probable positive relationship with Economics achievement.

The findings show that economics problem-solving was viewed as difficult compared to symbols and easier than 
graphs. The difficulty that the students faced in problem-solving using symbol knowledge can be interpreted as rote learning (Greeno, 1983). Malaysia Examination Council (2008) reported that Economics candidates' weakness is in the application of theory to solve economics problems. It can be seen that problem-solving is still difficult for the students in this study, which supports Cadenas (1999) findings.

This study implies that Economics teachers need to also give attention to problem-solving when teaching the Economics subject. According to Johnston and James (2000), students need to think abstractly and apply economic theories in their everyday lives. To be able to think abstractly and applying the thinking when confronting practical problems would be advantageous to ensure the students' proficiency in the Economics subject (Johnston, James, Lye, \& McDonald, 2000).

\section{Conclusion}

Based on the difficulty indices obtained, students who took the Economics test found it easier to answer the symbol test items compared to the graph and economic problem-solving items. Lucidly, the students' Economics achievement was less than satisfactory, which perhaps could be attributed to their weaknesses in quantitative literacy. In order to enhance meaningful learning of economics concepts among the pre university students, Economics teachers should gauge their students' pre-requisite knowledge with regards to symbols, graphs and economics problem-solving before designing learning and teaching activities in the Economics classrooms.

\section{Acknowledgement}

The authors would like to thank Universiti Utara Malaysia (UUM) for the financial funding of this project through PIBT Grant S.O. Code 12309 (2012).

\section{References}

Arnida, A. (2007). Miskonsepsi dalam pembelajaran konsep-konsep ekonomi di kalangan pelajar Tingkatan Empat (Unpublished master's thesis). Universiti Kebangsaan Malaysia.

Baker, R. S., Corbett, A. T., \& Koedinger, K. R. (2001). Towards a model of learning data representations. Paper present at the $23^{\text {rd }}$ annual conference. Retrieved from http://www.psychology.Nottingham,ac.uk/staff/1pzrsb/cogsci2001.pdf

Baumann, E. (1997). High school student's mispresentations of basic economic concepts. International Journal of Social Education, 11(2), 91-104.

Cadenas, H, G. (1999). Revitalize your teaching —Four key elements for success. Contemporary Education, 70(2), $5-7$.

Caviglia-Harris, J. L. (2005). Attendance and Achievement in Economics: Investigating the Impact of Attendance Policies and Absentee Rates on Student Performance. Journal of Economic and Finance Education, 4(2), $2-15$.

Çelik, D., \& Güneş, G. (2013). Different Grade Students' Use and Interpretation of Literal Symbols. Educational Sciences: Theory \& Practice, 13(2), 1168-1175.

Cohn, E., Cohn, S., Hult, R. E., Balch, D. C., \& Bradley, J. J. (1998). The Effects of Mathematics Background on Learning in Principles of Economics. Journal of Education for Business, 74(1), 18-22. http://dx.doi.org/10.1080/08832329809601655

Cubukcu, F. (2007). An investigation of reading strategies employed by trainee teachers. GEMA Online ${ }^{\mathrm{TM}}$. Journal of Language Studies, 7(2), 95-110.

Cucuo, A. A., \& Curcio. F. (2001). The role of representation in school mathematics: National Council of Teachers of Mathematics. Yearbook, Reston, VA: NCTM.

Dawson, P. (2014). Skills in Mathematics and Statistics in Economics and tackling transition. The Higher Education Academy. Retrieved from https://www.heacademy.ac.uk /sites/default/files/resources/TT_Maths_Economics.pdf

Diezmann, C. M. (2004). The role of operating premises and reasoning paths in upper elementary students' problem solving. Journal of Mathematical Behavior, 23(1), 63-73. http://dx.doi.org/10.1016/j.jmathb.2003.12.004

Dymock, S. (2005). Teaching expository test structure awareness. The Reading Teacher, 59(2), 177-182. http://dx.doi.org/10.1598/RT.59.2.7

Greeno, J. G. (1983). Forms of understanding in mathematical problem solving. In S. G. Paris, C. M. Olson, \& H. 
W. Stevenson (Eds.), Learning and motivation in the classroom (pp. 83-111). Hillsdale, NJ:Erlbaum.

Hansen, W. L. (2001). Expected Proficiencies for Undergraduate Economics Majors. Journal of Economic Education, 32(3), 231-242. http://dx.doi.org/10.1080/00220480109596105

Harris, R. L. (1996). Information graphics: A comprehensive illustrated reference. Atlanta: Management Graphics.

Johnston, C., McDonald, I., \& Williams, R. (2001). The Scholarship of Teaching Economics. Journal of Economic Education, 32(3), 95201. http://dx.doi.org/10.1080/00220480109596102

Johnston, C. G., \& James, R. H. (2000). An evaluation of collaborative problem-solving for learning economics. Journal of Economics, 31(1), 13-30.

Kaplan, R. M., \& Saccuzzo, D. P. (2001). Psychological Testing-Principles, Applications, and Issues (5th ed.). Belmont, CA: Wadsworth.

Khoo, Y. Y., \& Zakaria, K. (2005). Pembelajaran penyelesaian masalah secara kaedah kolaboratif dengan pemikiran kritis dan kreatif di kalangan pelajar tingkatan enam. Prosiding Seminar Pendidikan JPPG 2005: Education for Sustainable Development, 28-30 Ogos 2005, Pulau Pinang.

Khoo, Y. Y. (2008). Keberkesanan Kaedah Penyelesaian Masalah Secara Kolaboratif Dalam Kalangan Pelajar Ekonomi Tingkatan Enam ( $\mathrm{PhD}$ thesis). Universiti Sains Malaysia.

Kinzel, M. T. (2001). Analyzing college calculus students' interpretation and use of algebraic notation. Proceedings of the 21st Annual Meeting of the North American Chapter of the International Group for the Psychology of Mathematics Education, 1, 109-116.

Lowrie, T., \& Diezmann, C. (2005). Solving graphics problems: Student performance in junior grades. The Journal of educational Research, 100(6), 369-377. http://dx.doi.org/10.3200/JOER.100.6.369-378

Lowrie, T. (2005). Problem solving in out-of-school settings: Young children making sophisticated connections. Journal of Mathematical Behavior, 24, 275-286. http://dx.doi.org/10.1016/j.jmathb.2005.09.008

Luo, F. (2004). Understanding students' cognitive processes in solving algebraic problems. Retrieved from www.icme-organisers.dk/tsg09/FenqjenLuo.pdf

Malaysia Examination Council. (2011). Retrieved April 8, 2011, from http://www.mpm.edu.my

Malaysia Examination Council. (2008). Soalan Peperiksaan Mata Pelajaran Ekonomi Sijil Tinggi Pelajaran. Malaysia, Selangor: Majlis Peperiksaan Malaysia

Mayer, R. E. (1985). Structural analysis of science prose: Can we increase problem-solving performance? Hillsdale, NJ: Lawrence Erlbaum Associates.

Ongeri, J. D. (2009). Poor Student Evaluation of Teaching In Economics: A Critical Survey of the Literature. Australasian Journal of Economics Education, 6(2), 1-24.

Parkin, M. (2005). Economics (7th ed.). Oxford: Pearson.

Postigo, Y., \& Pozo, J. (2004). On the road to graphicacy: The learning of graphical representation systems. Educational Psychology, 24(5), 623-644. http://dx.doi.org/10.1080/0144341042000262944

Pugalee, D. K. (1999). Constructing a model of mathematics literacy. The Clearing House, 73(1), 19-22. http://dx.doi.org/10.1080/00098659909599632

Schuhmann, P. W., McGoldrick, K. M., \& Burus, R. T. (2005). Student Quantitative Literacy: Importance, Measurement, and Correlation with Economic Literacy. American Economist, 49(1), 49-66.

Skemp, R. R. (1982). Symbolic understanding. Mathematics Teaching, 99, 59-61.

\section{Copyrights}

Copyright for this article is retained by the author(s), with first publication rights granted to the journal.

This is an open-access article distributed under the terms and conditions of the Creative Commons Attribution license (http://creativecommons.org/licenses/by/3.0/). 